\title{
МЕЖОТРАСЛЕВОЙ УРОВЕНЬ ВЗАИМОДЕЙСТВИЙ В ЕВРАЗИЙСКОМ АГРОПРОДОВОЛЬСТВЕННОМ КОМПЛЕКСЕ
}

\author{
(c) 2020 Ермолова Ольга Васильевна \\ доктор экономических наук, профессор, зав. лабораторией \\ Институт аграрных проблем Российской Академии наук, Россия, Саратов \\ E-mail: ermolovarus@yandex.ru \\ (c) 2020 Кирсанов Владимир Викторович \\ кандидат экономических наук, ведущий научный сотрудник \\ Институт аграрных проблем Российской Академии наук, Россия, Саратов \\ E-mail: vkirs@yandex.ru \\ (c) 2020 Остапенко Татьяна Викторовна \\ кандидат экономических наук, старший научный сотрудник \\ Институт аграрных проблем Российской Академии наук, Россия, Саратов \\ E-mail: tanya_ostapenko_76@mail.ru
}

В статье анализируется развитие агропромышленной интеграции государств Евразийского экономического союза. Показаны различия в уровне развития агропродовольственного комплекса, самообеспеченности стран продовольствием. Приведены результаты исследования межотраслевых взаимодействий, выделены условия и факторы их углубления. Показаны основные направления углубления межотраслевых взаимодействий. Включение в глобальные цепочки добавленной стоимости рассматривается как фактор роста конкурентоспособности агропродовольственного комплекса.

Ключевые слова: Евразийский экономический союз, агропромышленная интеграция, торговля, производственная кооперация, цепочки добавленной стоимости

Введение. Межгосударственная интеграция оказывает большое влияние на экономическое развитие, уровень жизни населения. Стимулом межрегионального сотрудничества является взаимная выгода регионов. В условиях глобализации и рецессии региональная экономическая интеграция оказывает влияние на устойчивость развития агропродовольственного комплекса, связанных с ним отраслей, на развитие сельских территорий. Региональная экономическая интеграция содействует улучшению взаимодействия между странами, снижению издержек производства и трансакционных издержек. Особую значимость имеют межотраслевые аспекты исследования проблемы.

Цель исследования состоит в обосновании возможностей и направлений развития межотраслевых взаимодействий в Евразийском экономическом союзе.

Методика исследования. В ходе исследования использовались абстрактно-логический, экономико-статистический и монографический методы. Это дало возможность оценить динами- ку межотраслевых взаимодействий в евразийском агропродовольственном комплексе. В ходе исследования использовались основные положения структурного и ситуационного анализа, метод «затраты-выпуск».

Результаты исследований. Интеграционное объединение Евразийский экономический союз (ЕАЭС) является международной организацией, которая на всех этапах своего развития ставит задачи углубления региональной экономической интеграции, проведения сбалансированной структурной политики в ключевых отраслях экономики. Позитивные результаты реализации общей экономической политики находят отражение в укреплении продовольственной безопасности стран Союза, улучшении динамических и структурных параметров экономического роста. За период существования Союза с 2015 года прирост сельскохозяйственного производства составил 10,9\%. Важной частью реализации согласованной политики в сфере агропродовольственного комплекса и развития кооперации является сотрудничество по чув- 
ствительным сельскохозяйственным товарам [2]. К ним относятся товары, производство и взаимная торговля которыми имеют социальноэкономическое значение для устойчивого развития агропродовольственного комплекса и сельских территорий каждой из стран ЕАЭС. Несмотря на то, что страны Союза существенно отличаются по уровню развития и самообеспеченности продовольствием, общий рынок стран ЕАЭС практически по всем основным сельскохозяйственным товарам обеспечивается собственным производством. Уровень самообеспеченности основной сельскохозяйственной продукцией в 2018 году в целом по Союзу составлял 139,5\% по зерну, по маслу растительному - 145,3\%, овощебахчевым культурам - 95,8\%, картофелю - 98,4\%, по свинине, мясу птицы более 95\%. Исключение составляют фрукты, обеспеченность которыми составляет около $40 \%$. По ряду позиций - зерно, мясо свинины, мясо птицы, растительное масло, сахар - ЕАЭС может стать важным системообразующим элементом мирового продовольственного рынка.

Растущее влияние региональной экономической интеграции на устойчивость и эффективность развития агропродовольственных систем особенно проявляется в условиях обострения глобальных противоречий. Формирование и скоординированное развитие общих цепочек создания добавленной стоимости стран ЕАЭС облегчает межстрановые взаимодействия, содействует снижению издержек производства, трансакционных издержек, эффективной реализации ресурсного потенциала стран, развитию селективной специализации. Агропродовольственный комплекс стран ЕАЭС имеет значимый потенциал и большие возможности для формирования региональных фрагментов глобальных цепочек создания добавленной стоимости, что может обеспечить рост конкурентоспособности. В рамках Союза, согласно основным направлениям деятельности Правительства Российской Федерации на период до 2024 года, предполагается формирование эффективной системы разделения труда, производственной кооперации и совместной проектной деятельности. Особую значимость имеет определение направлений сотрудничества, по которым может быть получен максимальный интеграционный эффект. К перспективным направлениям развития интеграционных взаимодействий относятся совместные проекты с высокой добавленной стоимостью в молочном и мясном скотоводстве, птицеводстве, садоводстве и других отраслях.

Развитие интеграционных процессов в Союзе сдерживается недостаточной глубиной наднациональной кооперации. На кооперационные поставки приходится почти половина взаимного товарооборота в ЕАЭС. Наличие трансграничных барьеров ведет к тому, что преимущества евразийской интеграции используют в основном крупные компании. Дальнейшее развитие корпоративного взаимодействия будет эффективно при участии предприятий разных институциональных форм. Для активизации этого процесса необходима реализация проектов по созданию евразийской сети промышленной кооперации, субконтрактации и трансферу технологий [1].

Формирование цепочек создания добавленной стоимости в ЕАЭС на основе углубления интеграционных процессов предполагает либерализацию торговли, формирование открытой инвестиционной политики, привлечение новых взаимных инвестиций, обеспечение равных условий конкуренции для товаропроизводителей. Для углубления интеграции необходимо устранение ограничений ее развития, к которым относятся: низкое качество прогнозных балансов спроса и предложения, барьеры, препятствующие офшорному аутсорсингу компаний развитых стран в страны ЕАЭС и др. Важным направлением интеграции является содействие развитию совместного экспорта продовольствия в третьи страны, создание бренда «органическая продукция» ЕАЭС, реализация возможностей формирования приграничных агропродовольственных кластеров. Более эффективно должен быть использован потенциал евразийских институтов развития.

При исследовании перспектив интеграционных взаимодействий и развития производственной кооперации существенное значение имеет анализ вертикальной внутриотраслевой торговли. Для успешного встраивания в глобальные цепочки создания стоимости необходимо формирование региональных торговых соглашений, в которых национальные товаропроизводители могут эффективно использовать свои сравнительные преимущества. Доля взаимной торговли в общем объеме торговли стран ЕАЭС в 2014-2018 гг. составляла 13-17\%. Это значительно ниже минимального порога интеграционной устойчивости в 25\% [4]. Продовольственные товары и сельскохозяйственное сырье занимают 
большую долю в товарной структуре взаимной торговли стран ЕАЭС (14,7\%). В общем объеме взаимной торговли продовольствием на долю Беларуси в 2018 г. приходилось 51\%, России $37 \%$, Казахстана - 6,7\%, Армении - 4,1\%, Кыргызстана $-1,2 \%$. Положительное сальдо во взаимной торговле отмечается у Армении и Беларуси, только Казахстан является нетто-экспортером в торговле продовольственными товарами с третьими странами (табл. 1).

Во взаимной торговле государств-членов ЕАЭС в 2019 году преобладали товары промежуточного назначения (61,8\%). Расчеты доли промежуточного продукта в выпуске отраслей агропродовольственного комплекса государств показали, что в сельском хозяйстве стран ЕАЭС за исключением Беларуси наблюдалась стабильная динамика роста промежуточного продукта (табл. 2). В отраслях пищевой промышленности за 2012-2018 годы отмечалось снижение доли промежуточного потребления в конечном выпуске в большинстве стран. В России этот показатель рос, что можно связывать с увеличением количества переделов и усложнением структуры производства.

Несмотря на положительную динамику роста взаимной торговли в 2017-2018 гг., ее уровень не достиг показателя 2013 года. Низкие объ- емы взаимной торговли, уменьшение торговли с третьими странами, антироссийские санкции не способствовали формированию общих цепочек добавленной стоимости. В настоящее время внутри Союза не существует региональных цепей поставок, в которых взаимная торговля охватывала бы все стадии производства, хотя и существует потенциал для их образования.

Развитие процессов евразийской интеграции будет способствовать росту стабильности, инвестиционной привлекательности агропродовольственного комплекса стран Евразийского союза, удлинению продуктовых цепочек. Однако в последние годы появились риски дезинтеграционных тенденций. В их основе лежат незавершенность формирования единого экономического пространства Союза, существенные различия в уровне и структуре экономик входящих в него стран, неразвитость финансового сектора, что определяет различные цели и задачи инвестирования. Условия для невысокой инвестиционной привлекательности создают риски макроэкономической стабильности. Ограничивает сферу приложения капитала также недостаточность обеспечения сырьем, недозагрузка обрабатывающих и машиностроительных производств. Внутренний потребительский спрос имеет в последние годы неустойчивую ди-

Таблица 1. Изменение сальдо взаимной торговли продовольствием в ЕАЭС, млн. долл.

\begin{tabular}{|l|c|c|c|c|c|c|}
\hline \multirow{2}{*}{} & \multicolumn{3}{|c|}{ Сальдо взаимной торговли } & \multicolumn{3}{c|}{ Сальдо внешней торговли } \\
\cline { 2 - 7 } & 2014 & 2018 & 2019 & 2014 & 2018 & 2019 \\
\hline Армения & 8,8 & 66,6 & 137,8 & $-436,4$ & $-173,4$ & $-208,0$ \\
\hline Беларусь & 3667,7 & 3166,9 & 3169,0 & $-2927,4$ & $-2349,0$ & $-2285,0$ \\
\hline Казахстан & $-1283,1$ & $-1209,8$ & $-1475,0$ & $-412,6$ & 617,2 & 862,6 \\
\hline Кыргыстан & $-415,3$ & $-297,0$ & $-305,3$ & $-208,9$ & $-91,8$ & $-99,0$ \\
\hline Россия & $-1027,7$ & $-1482,5$ & $-1352,5$ & $-19697,7$ & $-3264,1$ & $-3741,2$ \\
\hline
\end{tabular}

Источник: Рассчитано авторами с использованием данных [3].

Таблица 2. Динамика доли промежуточного продукта в выпуске отраслей комплекса

\begin{tabular}{|l|c|c|c|c|}
\hline \multirow{2}{*}{} & \multicolumn{2}{|c|}{ Сельское хозяйство } & \multicolumn{2}{c|}{ Пищевая промышленность } \\
\cline { 2 - 5 } & 2012 & 2018 & 2012 & 2018 \\
\hline Армения & 33,2 & 33,8 & $\ldots$ &.. \\
\hline Беларусь & 56,4 & 62,4 & 80,6 & 76,8 \\
\hline Казахстан & 45,7 & 47,9 & 54,8 & 51,6 \\
\hline Кыргыстан & 69,1 & $69,3^{*}$ & 73,4 & $71,2^{*}$ \\
\hline Россия & 47,4 & 50,2 & 71,3 & 77,3 \\
\hline
\end{tabular}

*2016 год

Источник: Рассчитано авторами по данным национальных статистических органов 
намику роста, отражая волатильность денежных доходов населения.

Страны ЕАЭС испытывают сильную зависимость от импорта комплектующих и оборудования из третьих стран, от импорта семян овощных культур. Доля импортных семян составляет почти 70\% от их потребности. В настоящее время в России активизировались процессы импортозамещения в селекции и семеноводстве. Но пока эти отрасли не являются привлекательными для частных инвесторов, не имеют должной государственной поддержки. Сотрудничество в области селекции семян и животных, а также рост взаимных поставок является перспективным направлением развития интеграционных процессов. Снижение импортозависимости возможно на основе участия в международной сертификации семян по посевным и сортовым качествам. Стандартизация и сертификацию на основе международных норм является одним из приоритетов в стратегии включения в глобальные цепочки добавленной стоимости в области агропродовольственного комплекса.

Большую роль в развитии межгосударственной интеграции должны сыграть институты инновационного развития ЕАЭС - Евразийские технологические платформы, Евразийская сеть трансфера технологий, Евразийская цифровая платформа промышленной кооперации и субконтрактации и др. Использование созданных инновационных механизмов, формирование новых совместных финансовых институтов будет способствовать эффективным структурным сдвигам, облегчит переход к новой научнотехнологической модели развития, новым рынкам.

Страны ЕАЭС заинтересованы в привлечении как взаимных, так и внешних инвестиций. В научной литературе справедливо отмечается, что значение прямых иностранных инвестиций (ПИИ) неоднозначно. С одной стороны, они приносят в страну новые технологии, а с другой,- зарубежные инновации, не пригодные для совершенствования и развития, усиливают зависимость отечественных аграриев от импорта иностранных технологий. Плоды совершенствования технологий и инноваций при таком подходе остаются в руках разработчиков [5]. Агропромышленный комплекс занимает в ЕАЭС третье место среди ведущих комплексов по взаимным ПИИ. Инвесторы из России вкладываются в развитие проектов в Беларуси, казахские инвестиции направляются в Россию, а белорусские - в Казахстан. Объем белорусских инвестиций в Казахстане устойчиво растет с момента образования Таможенного союза. Рост кооперационных связей будет способствовать повышению инвестиционной привлекательности и росту взаимного товарооборота стран продовольственной продукции. Перспективными для совместной реализации являются проекты по производству продуктов с высокой добавленной стоимостью, товаров, не имеющих аналогов, проекты в наукоемких отраслях, в т.ч. в области биотехнологий.

Развитию интеграционных взаимодействий способствует формирование рыночной инфраструктуры, общего рынка капиталов, а также создание зоны свободных инвестиций Союза, интегрированной транспортной и логистической систем. Большое значение имеет формирование согласованных мер по включению малых и средних предприятий в уже существующие продуктовые цепочки. Важным условием привлечения потенциальных инвесторов, роста взаимных инвестиций является решение проблемы информационной открытости.

Устойчивость и перспективы развития отраслей и предприятий стран Союза определяется во многом удобством ведения бизнеса. Позиции государств-членов ЕАЭС в рейтинге Doing Business показывают разнонаправленную динамику (табл. 3). В 2019 году относительно 2014 года повысили свои позиции в рейтинге Казахстан (с 50 на 25 место), Россия (с 92 на 28 место), Беларусь (с 63 на 49 место). Одной из составляющей рейтинга Doing Business является оценка условий для экспорта и импорта. По этому показателю наиболее высокую позицию занимает Беларусь (25 место), Армения (46 место).

Позиции стран Союза, как показал анализ международных рейтингов, по многим позициям и в разной степени улучшились. Определенный вклад в улучшение позиций стран внесло развитие интеграционных процессов. Сложность и специфику их протекания определяет разноуровневость развития агропродовольственного комплекса стран. На скорость интеграции влияют не только национальные условия развития агропродовольственного комплекса, но и совместные усилия по развитию межрегиональных взаимодействий, развитию взаимной торговли, созданию конкурентных условий для бизнеса, формированию общих продуктовых цепочек добавленной стоимости. 
Таблица 3. Место стран ЕАЭС в международных рейтингах

\begin{tabular}{|l|c|c|c|c|c|c|c|c|}
\hline & \multicolumn{2}{|c|}{$\begin{array}{c}\text { Индекс глобальной } \\
\text { конкурентоспособ- }\end{array}$} & \multicolumn{2}{|c|}{$\begin{array}{c}\text { Индекс } \\
\text { глобализации }\end{array}$} & \multicolumn{2}{|c|}{$\begin{array}{c}\text { Глобальный индекс } \\
\text { инноваций }\end{array}$} & \multicolumn{2}{c|}{$\begin{array}{c}\text { Doing Business } \\
\text { Индекс легкости } \\
\text { ведения бизнеса }\end{array}$} \\
\hline & 2014 & 2019 & 2014 & 2019 & 2014 & 2019 & 2014 & 2019 \\
\hline Армения & 85 & 69 & 98 & 66 & 65 & 64 & 37 & 47 \\
\hline Беларусь & - & - & 75 & 67 & 58 & 72 & 63 & 49 \\
\hline Казахстан & 50 & 55 & 82 & 84 & 79 & 79 & 50 & 25 \\
\hline Кыргыстан & 108 & 96 & 87 & 85 & 112 & 90 & 68 & 80 \\
\hline Россия & 53 & 43 & 56 & 51 & 49 & 46 & 92 & 28 \\
\hline Количество стран & 144 & 141 & 207 & 203 & 143 & 129 & 189 & 190 \\
\hline в рейтинге & & & & & & & \\
\hline
\end{tabular}

Источник: Составлено авторами по данным $[6,7,8,9]$

Заключение. Эффективность межрегиональных взаимодействий стран ЕАЭС, развитие цепочек создания стоимости, достраивание отдельных элементов цепочек на уровне отдельных стран обусловлены географической близостью регионов, их исторической общностью. Эти процессы будут способствовать повышению устойчивости развития национальных агропродовольственных систем, укреплению их конкурентоспособности, расширению экспортных возможностей Союза. Интеграционные процессы в агропродовольственном комплексе на пространстве ЕАЭС направлены на создание эффективной конкурентной среды и обеспечение развития общего аграрного рынка.

Сегодня страны Союза существенно дифференцированы по уровню развития и самообеспеченности продовольствием, по степени участия во взаимной торговле, инвестиционной привлекательности, условиям ведения агробизнеса. В современных условиях реализация многих проектов развития бизнеса учитывает не только инфляционные ожидания бизнеса, но и уровень и динамику спроса на внутреннем рынке, который имеет тенденцию к снижению. Устранение спросовых ограничений даст новый импульс развитию интеграционных процессов.

Новый этап межрегиональных интеграционных взаимодействий связан с выстраиванием системы управления совместными кооперационными проектами, ростом взаимной торговли, формированием общих цепочек создания добавленной стоимости стран ЕАЭС. Большое значение имеет разработка и реализация совместных проектов выпуска продукции с высокой добавленной стоимостью (в мясном и молочном скотоводстве, птицеводстве, садоводстве и др.), инвестиционных и инновационных проектов модернизации производства, создание интегрированной транспортно-логистической инфраструктуры, а также содействие развитию совместного экспорта продовольствия в третьи страны. Общим условием эффективной интеграции является формирование ее основополагающих институтов, углубление наднациональной кооперации.

\section{Библиографический список}

1. Заседание Евразийского межправительственного совета 31 января 2020 года. Алма-Ата, Республика Казахстан. [Электронный ресурс]. Режим доступа: URL: http://government.ru/news/ (дата обращения 5.05.2020)

2. 5 лет Евразийскому экономическому Союзу. Евразийская экономическая комиссия, 2019.- 181 с. [Электронный ресурс]. Режим доступа: URL: http://eеc.eaeunion.org/ru/Documents/3057_EЭК_Книга 2019.pdf (дата обращения 25.05.2020)

3. Статистический ежегодник Евразийского экономического союза. Евразийская экономическая комиссия.Москва: 2019. - 438 с. [Электронный ресурс]. Режим доступа: URL: http://www.eurasiancommission.org/ru/ act/integr_i_makroec/dep_stat/econstat/Pages/statpub.aspx (дата обращения 25.05.2020)

4. Хейфец Б. А. Как модернизировать Евразийский экономический союз: Научный доклад. М.: Институт экономики РАН, 2019. - 45 с. [Электронный ресурс]. Режим доступа: URL: https://inecon.org/docs/2019/ Kheifets_ paper_2019.pdf (дата обращения 25.05.2020)

5. Хейфец Б.А., Чернова В.Ю. Потенциал экспортоориентированного импортозамещения в агропромышленном комплексе // Вопросы экономики. 2019. № 4. С. 74-89 
6. The Global Competitiveness Report. 2019. World Economic Forum. [Электронный ресурс]. Режим доступа: URL: http://www.cdi.org.pe/pdf/IGC/2019/ WEF_TheGlobalCompetitivenessReport2019.pdf (дата обращения 25.05.2020)

7. KOF Globalization Index Rankings 2019. KOF Swiss Economic Institute. [Электронный ресурс]. Режим доступа: URL: https://kof.ethz.ch/en/forecasts-and-indicators/indicators/kof-globalisation-index.html (дата обращения 25.05.2020)

8. Global innovation index 2019 Rankings. Report. 2019. Режим доступа: [Электронный ресурс]. URL: https://www. globalinnovationindex.org/gii-2019-report (дата обращения 25.05.2020)

9. Doing Business 2020. Comparing Business Regulation in 190 Economies. World Bank Group. [Электронный ресурс]. Режим доступа: URL: http://documents.worldbank.org/curated/en/688761571934946384/pdf/DoingBusiness-2020-Comparing-Business-Regulation-in-190-Economies.pdf (дата обращения 25.05.2020) 